\title{
Contribuições das disciplinas experimentais da licenciatura em Física para a formação dos saberes docente
}

\author{
Nelson Luiz Reyes Marques*, Gilberto Orengo**
}

\section{Resumo}

As pesquisas apontam lacunas na formação inicial de professores, principalmente, devido a separação entre os saberes disciplinares e os saberes pedagógicos. Também mostram que as aulas de laboratório estão associadas a roteiros fechados e centradas no modelo aplicacionista, priorizando os conhecimentos específicos da Física e o método científico, em detrimento de uma formação pedagógica adequada para a sua utilização no Ensino Médio, ignorando seu potencial mediador para a Transposição Didática dos saberes. Este trabalho apresenta resultados de uma pesquisa desenvolvida com o objetivo de avaliar as contribuições das disciplinas de Física Experimental das Licenciaturas em Física para a construção dos saberes docentes, a partir dos conceitos de saberes propostos por Tardif e da Transposição Didática na visão de Chevallard. A metodologia de pesquisa foi o estudo de caso qualitativo, referenciado em Stake. Como instrumento para coleta de dados foram utilizados questionários, aplicados online para 65 professores de todo o Brasil, e entrevistas semiestruturas, aplicadas para 16 professores formados nas universidades do Rio Grande do Sul que apresentam Licenciatura e Bacharelado. A pesquisa mostrou a necessidade de uma atualização das disciplinas de Física Experimental da Licenciatura em Física, a fim de que contribuam mais significativamente para a formação dos professores que atuam no Ensino Médio.

Palavras-chave: Ensino de Física; formação de professores; Física Experimental.

* Professor e Pesquisador do Programa de Pós-graduação em Ciências e Tecnologias na Educação (PPGCITED) do Campus Pelotas Visconde da Graça do Instituto Federal Su-rio-grandense (IFSUL), Pelotas, RS, Brasil. E-mail: nelsonmarques@ifsul.edu.br

* Professor e Pesquisador do Programa de Pós-graduação em Ensino de Ciências e Matemática (PPGECIMAT) da Universidade Franciscana (UFN), Santa Maria, RS, Brasil. E-mail: g.orengo@gmail.com

Recebido em: 04/10/20 - Aceito em 03/03/2021

https://doi.org/10.5335/rbecm.v4i1.12246

http://creativecommons.org/licenses/by-nc-nd/4.0 


\section{Introdução}

Estudos apontam diferentes desafios para serem superados pelo ensino de Ciências, tais como: a pouca participação dos professores na construção de novos conhecimentos didáticos (CACHAPUZ et al., 2011); a submissão de currículos e programas a tratamentos didáticos obsoletos, em desacordo com o processo de fazer e de pensar ciência (CASTRO, 2004); formações pedagógicas estruturadas na separação entre conteúdos científicos e pedagógicos (CACHAPUZ et al., 2011); desconsideração da epistemologia da ciência e uma influência muito limitada da Didática da Ciência sobre as atividades escolares, representando um sério obstáculo para o desenvolvimento desse corpo do conhecimento (FOUREZ, 2003; CACHAPUZ et al., 2011, YAMAZAKI e YAMAZAKI, 2017).

A pesquisa de Silva e Rosa (2016) identificou a necessidade de "propor atividades que superem a visão de aulas de laboratório como aquelas associadas a um roteiro-guia altamente estruturado e que não permite ao aluno recorrer a sua criatividade e ao pensamento crítico durante a execução das atividades". A realização de atividades experimentais pelos alunos só possibilita aprendizagem se contar com a participação ativa do professor, que oriente a realização em todas as suas etapas: a exposição de seus objetivos e de seus fundamentos teóricos, a realização da montagem, a adoção dos procedimentos experimentais, a realização das medidas, a análise dos dados, a obtenção de resultados e a apresentação de conclusões. Somente assim, podemos considerar a prática experimental como mediadora da Transposição Didática dos saberes físicos.

Para Garcia e Pozo (2017) as disciplinas comuns dos cursos de licenciatura e bacharelado não atendem as necessidades da licenciatura, pois há reduzida diversidade de estratégias nas disciplinas da área específica, e apesar de algumas disciplinas pedagógicas terem práticas diversificadas, muitos licenciados incorporam a visão acadêmica preponderante no curso, repetindo o modelo dos professores que tiveram, inclusive nas aulas experimentais.

Os professores são protagonistas que possuem saberes e um saber-fazer e dão provas disso em seus atos cotidianos. Apesar das pesquisas mostrarem que o professor é o agente responsável para realizar as mudanças em sala se aula, os currículos de formação costumam desvalorizá-lo, sendo tratado como incompetente e é ensinado a ele o que deve fazer, sem valorizar a sua cultura e o seu saber expe- 
riencial (TARDIF, 2018). O próprio autor entende que os cursos de formação inicial de professores são idealizados segundo um modelo aplicacionista do conhecimento, em que os futuros docentes passam anos a assistir aulas baseadas em disciplinas e constituídas de conhecimento proposicional, e, quando a formação termina, eles começam a trabalhar sozinhos, aprendendo o seu ofício na prática e constatando, na maioria das vezes, que esses conhecimentos proposicionais não se aplicam a ação cotidiana.

Nesse contexto, Moreira (2018) defende a necessidade de atualizar o currículo e o ensino na Licenciatura em Física de modo que tenha mais saberes da Física, porém de uma perspectiva contemporânea, conceitual, epistemológica e de Transposição Didática. Nessa perspectiva o Conselho Nacional de Educação, com o objetivo de mudar o modelo de formação de professores construída no modelo disciplinar, baseado na racionalidade técnica, vem estabelecendo, através das Diretrizes Curriculares Nacionais para a Formação de Professores da Educação Básica, desde 2002, que o licenciando deve ser capaz de relacionar teoria e prática e que as questões pedagógicas devem permear todo o curso e não apenas concentrar-se nos anos finais. A implementação das Diretrizes Curriculares deveria ter rompido a dicotomia teoria e prática, o que não se confirmou.

O presente trabalho buscou compreender se as disciplinas experimentais criam condições para uma Transposição Didática adequada aos objetivos do uso dessas práticas no processo de ensino e aprendizagem no Ensino Médio "como elemento mediador para ensinar os conteúdos de Física e não mais o método experimental" (ALVES FILHO, 2000) e a sua contribuição para a formação dos saberes oriundos da formação profissional do professor.

\section{Embasamento teórico}

Nossa pesquisa é um estudo de caso no qual investigamos as práticas de ensino de Física, em especial as práticas experimentais, adotadas por professores de Física que atuam no Ensino Médio e as contribuições das disciplinas de Física Experimental (Laboratório de Física) dos Cursos de Licenciatura em Física para essas práticas, utilizando como referenciais teóricos os conceitos da teoria de Tardif (2018) e a Teoria da Transposição Didática de Chevallard (2005). 


\section{Saberes Docentes de Tardif}

Para Tardif (2018) os professores de profissão possuem saberes específicos que são mobilizados, utilizados e produzidos por eles no âmbito de suas tarefas cotidianas. Tardif (2018) caracteriza o professor ideal como alguém que deve conhecer sua matéria, sua disciplina e seu programa, além de possuir certos conhecimentos relativos às ciências da educação e à pedagogia e desenvolver um saber prático baseado em sua experiência cotidiana com os alunos.

O saber docente é um saber plural, que não se restringe a uma função de transmissão dos conhecimentos já construídos, formado pelo amálgama, mais ou menos coerente, de saberes oriundos da formação profissional (saberes profissionais) e dos saberes disciplinares, curriculares e experienciais (TARDIF, 2018, p. 36). O autor salienta que os saberes do professor (Figura 1) são construídos e utilizados em função dos diferentes tipos de raciocínio que expressam a flexibilidade da atividade docente diante de fenômenos irredutíveis a uma racionalidade única, como por exemplo a da ciência empírica (TARDIF, 2018, p. 66).

Figura 1: Saberes docente

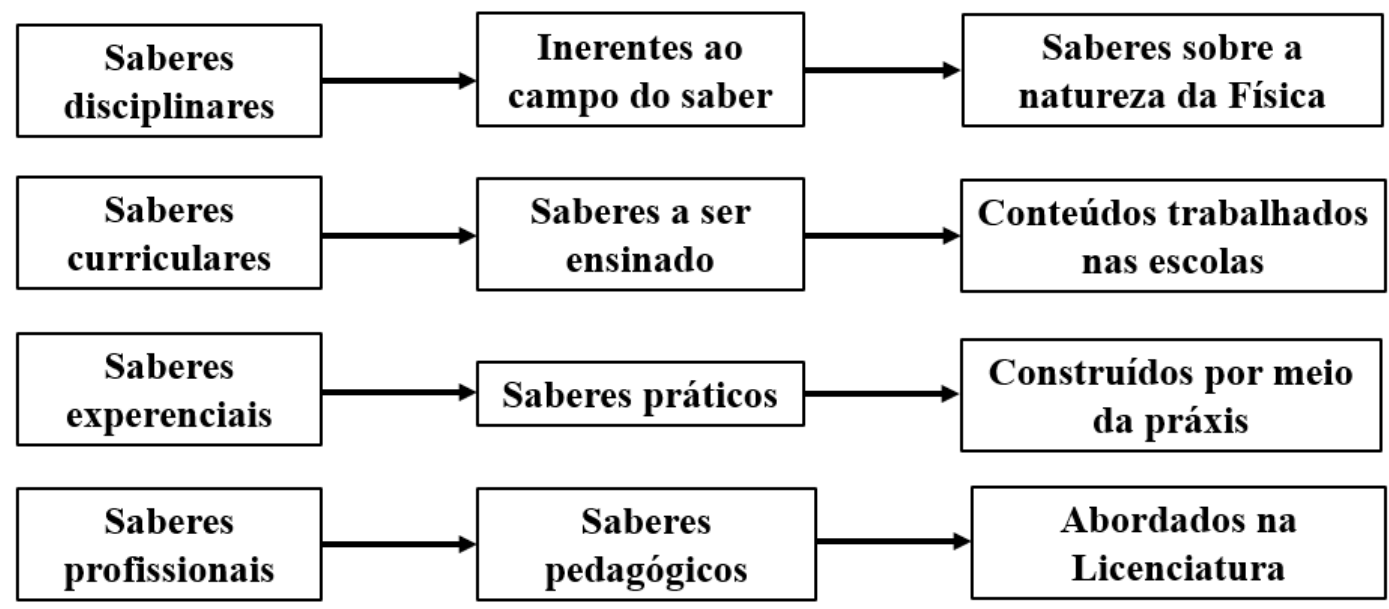

Fonte: autor

Para Tardif (2018) ensinar é desencadear um programa de interações com um grupo de alunos, a fim de atingir determinados objetivos educativos relativos à aprendizagem de conhecimentos e à socialização. Os saberes experenciais surgem 
como um núcleo vital do saber docente e a partir dele, os professores tentam transformar suas relações de exterioridade com os saberes em relações de interioridade com sua própria prática. "Nesse sentido, os saberes experenciais não são saberes como os demais; são, ao contrário, formados de todos os demais, mas retraduzidos, "polidos" e submetidos às certezas construídas na prática e na experiência" (TARDIF, 2018, p. 54).

\section{Teoria da Transposição Didática de Chevallard}

Chevallard (2005) explica que a Transposição Didática é um processo através do qual o saber produzido pelos cientistas (o Saber Sábio) se transforma naquele que está contido nos programas e livros didáticos (o Saber a Ensinar) e, principalmente, naquele que realmente aparece nas salas de aula (o Saber Ensinado/Saber Aprendido). Assim, a Transposição Didática pressupõe a existência de um processo no qual um conteúdo do saber tendo sido designado como saber sábio, sofre, a partir daí, um conjunto de transformações adaptativas que o levam a tomar lugar entre os objetos de ensino.

Chevallard (2005) distingue duas fases de Transposição Didática (Figura 2), a externa em que o saber sábio é transformado em saber a ensinar; e a interna em que o saber a ensinar é convertido na escola, com a intervenção de diversos entes da noosfera, em saber ensinado.

Figura 2: Fases da Transposição Didática.

Saber Sábio: é o saber apresentado nas palavras originais de seus autores.

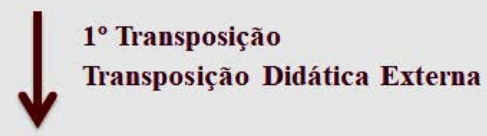

Saber a Ensinar: aquele entendido como conteúdo escolar.

O saber a ensinar também está presente nos livros textos.

$2^{\circ}$ Transposição

Transposição Didática Interna

Saber Ensinado: aquele que realmente acontece em sala de aula Fonte: Autor. 
Nesse contexto, entre o conhecimento que é produzido e entendido como saber e o que é ensinado na sala de aula, existem diferenças significativas. Uma possibilidade para entender este processo de transformações é fazer uso do conceito de Transposição Didática. Assim, a Transposição Didática é o conjunto de ações que torna um saber "sábio" em saber ensinável (ALVES FILHO, 2000).

\section{Metodologia de pesquisa}

A pesquisa utilizou a metodologia do tipo estudo de caso instrumental na concepção de Stake (2007, 2009). A opção pelo estudo de caso na concepção de Stake se deve ao seu compromisso epistemológico construtivista, onde o conhecimento é construído, ao invés de descoberto. Estudamos uma situação específica (como as práticas experimental de Física vivenciadas na formação inicial contribuíram para a sua formação do licenciando como professor) na sua particularidade e complexibilidade.

$\mathrm{Na}$ fase de análise sistemática dos dados, seguindo as orientações de Stake (2007), utilizamos como estratégicas a agregação categorial e a interpretação direta. O primeiro passo na tarefa de análise é organizar todo o material coletado, separando-o em diferentes arquivos segundo as fontes de coleta ou arrumando-o em ordem cronológica. A elaboração do relatório final é um grande desafio na condução do estudo de caso, pois exige certa habilidade de escrita por parte do pesquisador.

Para Stake (2009) o pesquisador ao examinar os dados que tem em mãos utiliza suas próprias experiências individuais como base para a análise e através dessas interpretações chega às conclusões que lhe parecem mais acertadas, produzindo generalizações a respeito do assunto em questão. Tais ideias são apresentadas aos leitores que também realizam suas generalizações que surgem com base na interpretação pessoal do próprio leitor a respeito do que foi exposto sobre o caso. Por esse motivo, é necessário que o pesquisador descreva de forma rica e mais fiel possível o caso e todo seu contexto, para que o leitor possa acompanhar o desenvolvimento das ideias expostas pelo pesquisador ao término do estudo, enquanto paralelamente ele próprio interpreta à sua maneira o caso em questão.

A coleta de dados foi feita através da aplicação de um questionário online respondido por 65 professores de todo o Basil e entrevistas semiestruturadas respondidas por 16 professores formados nas universidades do estado do Rio Grande do Sul que 
apresentam cursos de Licenciatura e Bacharelado em Física. Todos os pesquisados atuam no Ensino Médio.

\section{Contribuições das disciplinas de Física Experimental das licenciaturas em Física para a construção dos saberes docentes dos futuros professores}

Para Tardif e Raymond (2000) a noção de saber tem um sentido amplo que engloba os conhecimentos, as competências, as habilidades e as atitudes dos docentes, ou seja, aquilo que costumamos chamar de saber, de saber-fazer e de saber-ser. Isto se reflete em sua compreensão de que os saberes docentes são plurais, heterogêneos, personalizados, situados, pois carregam as marcas do ser humano e são oriundos de diversas fontes sociais, tais como aquelas decorrentes da trajetória pré-profissional dos professores e da formação universitária.

É importante ressaltarmos que os saberes disciplinares, correspondentes aos diversos campos do conhecimento sob a forma de disciplina, são saberes sociais definidos e selecionados pela instituição universitária e incorporados na prática docente. Compreendem a formação acadêmica, que não estão ligados aos saberes da educação (saberes da formação profissional), tais quais: Física, Matemática, História, Literatura, Biologia, etc.

Nesse sentido, os saberes docentes explicitados pelos professores permite a nós identificar que a principal contribuição das disciplinas de Física Experimental está nos saberes relacionados ao método experimental, de pouca importância para a atuação do professor no Ensino Médio. Houve também uma contribuição relevante para os saberes ligados aos conteúdos da Física Clássica e Moderna (saber disciplinar), porém destacamos a falta de compromisso com os saberes pedagógicos, ou seja, não existe uma preocupação integral com os saberes provenientes da formação profissional para o magistério. A pesquisa mostra que os professores não percebem como são significativas as contribuições das disciplinas de Física Experimental para a sua atuação profissional e, na visão deles, reforçam os saberes disciplinares das disciplinas já vistos, em detrimento dos demais.

A partir dessa análise, vemos que a preocupação das disciplinas de Física Experimental é com o saber disciplinar e, que desprezam os saberes pedagógicos (saberes profissionais). Nos relatos inclusive percebemos o desprezo aos saberes da formação profissional. Também não encontramos situações que mostrem preocupação com os 
saberes experienciais, ou seja, não se percebe a proposta de atividades nas quais os licenciandos pudessem explorar as atividades experimentais na perspectiva do Ensino de Física. Esse modelo é aplicacionista e idealizado segundo uma lógica disciplinar e não segundo uma lógica da formação profissional centrada no estudo das tarefas e realidades do trabalho dos professores.

A lógica disciplinar é regida por questões de conhecimento e não por questões de prática. Em uma disciplina, aprender é conhecer enquanto em uma prática, aprender é fazer e conhecer fazendo. No modelo aplicacionista, o conhecer e o fazer são dissociados e tratados separadamente em unidades de formação distintas e separadas, o que consideramos um equívoco epistemológico.

Para Tardif (2000, 2018) o problema do modelo utilizado na universidade, centrado no saber disciplina, reside no fato de que os professores não fazem a relação das disciplinas entre si e elas acabam se constituindo em unidades de formação estanques, dissociadas e fechadas em si mesma. Para o autor, de um modo geral, os professores universitários são pesquisadores e têm interesse em abandonar a esfera da formação para o magistério e se dedicar principalmente a sua pesquisa e a formar outros pesquisadores, por meio de uma formação de alto nível, de doutorado ou pós-doutorado os quais não se destinam ao ensino na Educação Básica.

A partir da análise das respostas, percebemos que a grande maioria dos professores aponta, que durante a formação inicial, deve haver diferenciação nas disciplinas de Física Experimental comuns entre a Licenciatura e o Bacharelado. Entendemos que isto, na visão do professor formador, é coerente pelo fato de serem os saberes disciplinares aqueles mais destacados pelos professores entrevistados como objetivos principais das disciplinas de Física Experimental, na sua formação. Os professores entrevistados mencionam a necessidade de outros saberes para a atuação profissional e atribuem, como um dos problemas, a desarticulação entre os docentes formadores, principalmente entre as disciplinas da Física e as pedagógicas (colocadas como disciplinas da Educação). Eles acreditam que os professores da Física valorizam apenas o conteúdo e o método experimental.

A formação inicial deve ser baseada, também, na análise da prática, das tarefas e dos conhecimentos dos professores, procedendo-se por meio de um enfoque reflexivo, levando-se em conta as condições reais do trabalho docente. Acreditamos que os professores formadores têm que ter a consciência que os licenciandos, quando forem atuar nas escolas, utilizam constantemente conhecimentos da Física (saberes 
disciplinares), saberes pedagógicos (saberes profissionais), saberes construídos por meio da práxis (saberes experienciais) e saberes relativos aos conteúdos que são trabalhados na escola (sabres curriculares), ou seja, assim precisam criar situações nas quais essa gama de saberes sejam mobilizados. É necessário a compreensão que os saberes sobre educação e sobre pedagogia não geram os saberes pedagógicos, ou seja, estes só se constituem a partir da prática, que os confronta e os reelabora (PIMENTA 2000). Como mostra os documentos oficiais, a prática não pode ficar restrita a disciplinas de instrumentação e aos estágios, elas devem acompanhar toda a formação na Licenciatura.

Também ressaltamos que os professores fazem uso na sua atuação profissional dos saberes provenientes da formação escolar anterior, que chamamos de saberes provenientes da formação ambiental. Esses saberes são interiorizados durante a sua história de vida escolar por meio de crenças e valores sobre como é uma sala de aula e o que se espera de um bom professor, por exemplo. Para Tardif (2018), tais concepções "estruturam a sua personalidade e suas relações com os outros e são reatualizados e reutilizados, de maneira não reflexiva, mas com grande convicção, na prática de seu ofício" (TARDIF, 2018, p.72). A esse respeito Yamazaki et al. (2017) apontam que a incorporação de uma concepção de ensinar Física se inicia antes dos cursos de formação inicial docente, enquanto o pretendente a professor se encontra ainda na condição de aluno do ensino básico, portanto, sendo influenciada desde o Educação Básica até os cursos de graduação.

Nessa perspectiva, salientamos que essa formação ambiental surge de experiências repetidas e se adquire de forma não reflexiva como algo natural, escapando assim à crítica e transformando-se em verdadeiro obstáculo. Defendemos que as Licenciaturas devem ter uma formação alicerçada numa reflexão crítica que, concomitantemente, demonstre a insuficiência dessa formação e ofereça alternativas realmente viáveis de procedimentos didáticos. Reiteramos que essa utilização se deve ao distanciamento entre os saberes oriundos da formação universitária e os saberes mobilizados nas escolas da Educação Básica.

Com isso, temos que ter claro que os saberes experienciais do professor de profissão, longe de serem baseados unicamente no trabalho em sala de aula, decorrerem, em grande parte, de preconcepções do ensino e da aprendizagem herdadas da história escolar (formação ambiental). Acreditamos, baseado nas pesquisas discutidas anteriormente, que os professores formadores não possuem muitos saberes experienciais 
relativos às atividades experimentais na Educação Básica, tendo em vista a pouca ou nenhuma utilização dessas atividades na sua formação nesse nível de ensino e, também por não terem exercido à docência nesse nível de ensino.

Para isso, concordamos com Sabino e Pietrocola (2016), que a instituição de ensino superior precisa potencializar os saberes da formação profissional, os curriculares e os experienciais, enfraquecendo assim o controle que os saberes pessoais e da formação anterior têm sobre o indivíduo, o que diminuiria os fatores imponderáveis da profissão e para Tardif (2018) se isso for bem sucedido, o ensino deixará, então, de ser um ofício para tornar-se uma verdadeira profissão, como à profissão de médico ou às profissões de engenheiro e de advogado.

A análise dos dados também mostrou que os saberes curriculares da Física para o Ensino Médio, que correspondem aos discursos, objetivos, conteúdos e métodos, necessitam ser revistos, principalmente por carecer de uma modernização dos conteúdos e, também, se adequar a baixa carga horária da disciplina. Concordamos com Moreira (2018) ao afirmar que o currículo de Física do Ensino Médio precisa ser atualizado, incorporando tópicos de Física moderna e contemporânea, não apenas para constar na lista de conteúdos, mas sim para que seja ensinada a Física de hoje usando situações da vida real, uma Física para a cidadania. Para isso, precisamos repensar a formação inicial do professor.

Acreditamos que a formação inicial do professor de Física deve incorporar situações práticas desde o início da formação acadêmica, o que já é previsto na legislação, criar espaços no currículo dos cursos universitários que possibilitem troca de experiências entre professores da Educação Básica e os licenciados, além do estágio (também previsto na legislação) e desenvolvimento de pesquisas acadêmicas que favoreçam a participação ativa dos professores da Educação Básica. A formação deve assumir um papel que vai além do ensino que pretende apenas uma mera atualização científica, pedagógica e didática e se transforme na possibilidade de criar espaços de participação, reflexão e formação (IMBERNÓN, 2011).

Temos convicção de que a formação inicial deva produzir uma nova visão de ensino e aprendizagem que exija dos futuros professores além da aprendizagem de teorias e métodos de ensino, também, uma mudança nos hábitos adquiridos durante toda a sua vida escolar, de modo que eles devem aprender a ensinar de uma forma que eles mesmos não foram ensinados. 
Transposição Didática e as práticas experimentais

A Transposição Didática, proposta por Chevellard (2005), se mostra como um instrumento capaz de analisar o processo através do qual o saber produzido pelos cientistas (o Saber Sábio) se transforma naquele presente nos programas e nos livros didáticos (o Saber a Ensinar) e, principalmente, naquele que realmente aparece nas salas de aula (o Saber Ensinado/Saber Aprendido), ou seja, analisa as modificações que o saber produzido pelos cientistas sofre até este ser transformado em um objeto de ensino.

Durante o desenvolvimento da pesquisa contatamos que a maioria dos professores não possuem uma concepção clara do processo de Transposição Didática. Particularmente, ao analisar as entrevistas, observamos que as respostas são monossilábicas e não refletem o que é a Transposição Didática.

Para Cheverlard (2005) um conceito ao ser transferido, transposto de um contexto ao outro, passa por profundas modificações. Ao ser ensinado, todo conceito tem que manter semelhanças com a ideia original presente em seu contexto da pesquisa, porém adquire outros significados próprios do ambiente escolar no qual será alojado, ou seja, trata-se de novos conhecimentos capazes de responder a dois domínios epistemológicos diferentes: a ciência e a sala de aula. A Transposição Didática possibilita que o conhecimento seja reconstruído em sala de aula e possua uma linguagem adequada à compreensão dos estudantes, de forma que seja possível a construção desse conhecimento.

Durante a execução da nossa pesquisa, em diversos momentos, os professores relataram que os roteiros das atividades experimentais na licenciatura, apresentavam as leis experimentais antes da teoria e isso pode criar uma expectativa falsa sobre a produção do conhecimento. Acreditamos que essa apresentação tenha como objetivo ingênuo valorizar o trabalho experimental e se trata de um equívoco epistemológico onde se vê nitidamente a presença do credo positivista, tão criticado no século passado. Acreditamos, assim como Alves Filho (2000) que "essa visão produz um comprometimento do saber sábio e da sua reconstrução, mostram apenas a valorização do empírico como sendo o primeiro passo para a reconstrução da teoria" (ALVES FILHO, 2000, p. 241).

Mais de $70 \%$ dos entrevistados, mesmo os que não fazem uso das atividades experimentais, relatam que preferem começar as aulas com alguns dados oriundos 
da experimentação, para depois desenvolver a teoria. Esse procedimento cria, mesmo que involuntariamente, uma visão falsa da produção do conhecimento. Vários professores relatam que preferem iniciar o conteúdo através de um fato observado em experiência (fazem apenas uma descrição). Podemos exemplificar esse fato nos conteúdos de Empuxo, Dilatação dos Sólidos, Magnetismo, entre outros. Esse fato já tinha sido descrito por Alves Filho (2000) para vários tópicos dos livros didáticos.

Concordamos com Alves Filho (2000) ao afirmar que o desmonte epistemológico do saber sábio e sua reconstituição demonstram claramente a valorização do empírico como sendo o primeiro passo para a construção teórica. "O credo positivista se faz presente na sequência do texto didático" (ALVES FILHO, 2000, p. 241.) e podemos complementar, que também está presente nas aulas do Ensino Médio e nas aulas de Física Experimental das Licenciaturas.

Nesse contexto, os professores entrevistados relatam que as suas aulas são, na grande maioria, tradicionais e apoiadas no livro didático com a resolução dos exercícios do próprio livro ou listas adicionais. Acreditamos que, muitas vezes, ocorre a utilização do livro de maneira não reflexiva e isso nos leva a entender parcialmente a valorização do empírico para a construção da teoria.

Também observamos que os poucos professores que dizem utilizar, mesmo que esporadicamente, alguma atividade experimental (mesmo de demonstração), colocam como objetivo principal que os alunos observem o fenômeno para depois introduzirem os conceitos fundamentais. Novamente estamos diante de um equívoco epistemológico e até poderíamos dizer que apresentam uma concepção ingênua da Ciência e de desvalorização do Saber Sábio. Apresentam a prática experimental com um viés de valorização apenas do empírico.

Este mesmo fato é descrito pelos entrevistados em relação as disciplinas de Física Experimental da Licenciatura, onde, a partir da experimentação (com ênfase na observação) tentam fazer a reconstrução de leis e princípios, dando a noção equivocada, de que as teorias derivam de dados empíricos oriundos da observação. Reiteramos que essa visão desqualifica o Saber Sábio e o método experimental passa a ser o objeto da transposição.

Percebemos que as disciplinas experimentais da licenciatura estão totalmente dissociadas das disciplinas teóricas. Isto confirma que o objetivo maior é o ensino do método experimental. Alves Filho (2000) discute que: 
[...] os criadores de atividades práticas de laboratório selecionam, de uma ampla gama de opções, e apresentam aos alunos apenas um pequeno subconjunto de problemas e variáveis. O professor controla o equipamento do laboratório, o espaço, materiais e até o máximo de erro de medição que pode ser tolerado (ALVES FILHO, 2000, p. 246).

Esse controle do professor, chegando ao limite de determinar o erro máximo admissível nas medições, mostra que o objetivo do laboratório está dirigido ao ensino de procedimentos, técnicas e habilidades experimentais, ou seja, o método experimental se tornou o Saber Sábio. Apesar de em cada aula ser tratado um tópico da Física, o objetivo é sempre o método. Isso reforça nossa percepção de que o objeto de ensino do laboratório é o método experimental, não o saber físico. Entendemos que para mudar esse cenário é fundamental colocar as atividades experimentais no processo de ensino e não apenas a importância do método experimental.

Defendemos a transformação das atividades experimentais em um instrumento que ofereça objetos concretos de mediação entre a realidade e as teorias científicas, e com isso, estamos nos opondo radicalmente aos exercícios comprovatórios atualmente propostos na formação de professores. Essa transformação permitirá a participação ativa do aluno em situação de investigação real, a proposta na forma de desafio, o instigará na busca de uma resposta correta, entendendo o correto como exercício de um procedimento que se baseia em uma hipótese teórica para a resolução de um problema científico (ALVES FILHO, 2000).

Entendemos, assim como Rosa (2003), que as atividades experimentais no Ensino de Física não podem ficar restritas a contribuir apenas com a aquisição de conhecimentos,

[...] mas também e inclusive com discussões envolvendo as diferentes dimensões do saber escolar. Ou seja, as atividades desenvolvidas em laboratório necessitam de uma identificação não só com os elementos vinculados aos domínios específicos dos conteúdos, mas com questões de ordem social, humana, ética, cultural e tecnológica presentes na sociedade contemporânea (ROSA, 2003).

As disciplinas de Física Experimental deveriam proporcionar que os alunos assumissem uma postura mais participativa, mais reflexiva e interativa durante as atividades desenvolvidas e não apenas ficarem presos a roteiros e relatórios estruturados que não favorecem a criatividade. Partindo de uma proposta construtivista, o trabalho dessa forma permite determinação das ideias prévias dos estudantes e se torna possível, através de um diálogo questionador, perceber quais as argumentações 
são utilizadas para explicar o fenômeno envolvido. As diferentes argumentações permitirão ao professor mapear quais os equívocos de interpretação e surge uma oportunidade importante para o professor discutir essas ideias.

Acreditamos que dessa maneira as práticas experimentais devem se constituir de atividades que permitam gerar uma negociação sobre conhecimento, para a construção do saber físico e assim elas contribuírem para a transposição desses saberes em sala de aula.

Assim como Alves Filho (2000) acreditamos que:

A atividade experimental deve ser entendida como um objeto didático, produto de uma Transposição Didática de concepção construtivista da experimentação e do método experimental, e não mais um objeto a ensinar. Como objeto didático sua estrutura deve agregar características de versatilidade, de modo a permitir que seu papel mediador se apresente em qualquer tempo e nos mais diferentes momentos do diálogo sobre o saber no processo ensino e aprendizagem. E, principalmente, é um objeto de ação que, manipulado didaticamente pelo professor, irá se inserir no discurso construtivista facilitando a indução do fenômeno didático que objetiva o ensino de saberes (ALVES FILHO, 2000, p. 263).

Queremos deixar claro que não estamos negando a importância do método experimental ao longo do processo de formação na Licenciatura e que acreditamos que nem tudo deva girar em torno de atividades experimentais. Acreditamos, assim como Alves Filho (2000), que o método experimental deva ter um espaço e procedimentos específicos para ser ensinado, através de atividades experimentais próprias, e didaticamente explicitadas.

O que deve ser considerado indispensável no processo didático é a presença da atividade experimental na Transposição Didática do saber ensinado e o professor se torna responsável por escolher a atividade experimental e determinar como ela será trabalhada. Entendemos a experimentação, como um objeto didático, produto de uma Transposição Didática e não mais como um objeto a ensinar.

É preciso que os formadores universitários auxiliem seus alunos a entenderem os processos de Transposição Didática, ou seja, como os conteúdos de Física apreendidos no Ensino Superior são transpostos para o Ensino Médio e que isso é diferente de fazer simplificações. Tem que mostrar que no processo de transformação do saber sábio para o saber a ensinar devem obedecer cinco regras: (1) modernizar o saber escolar; (2) atualizar o saber a ensinar; (3) articular o saber "novo" com o "antigo"; (4) transformar um saber em exercícios e problemas e (5) tornar um conceito mais compreensível. 
A ideia que nos parece mais coerente, seguindo os estudos de Chevallard (2005), é de que a grande maioria dos professores não faz a Transposição Didática, ele apenas participa de uma etapa dela, sendo um instrumento de divulgação do saber, ensinando e perpetuando a transmissão dos saberes. Para mudarmos esse cenário é fundamental que o professor dentro da situação de ensino faça uma repersonalização, uma recontextualização e uma retemporalização dos saberes.

Para o professor produzir um novo saber que resulte no saber ensinado, realizando assim a transposição didática interna, ele necessitará cumprir algumas exigências, tais como: resgatar a contextualização histórica da produção do saber sábio, diminuir o excesso do artificialismo e da neutralidade do saber a ensinar e do saber ensinado; conhecer as atualizações científicas publicadas em fontes reconhecidas, inteirando-se do que há de novo com o saber em questão; conhecer a epistemologia do saber em questão; aprimorar as abordagens e contextualizações do saber; dominar a linguagem adequada do saber para reescrevê-lo conforme o vocabulário dos alunos e o estágio de compreensão deles.

Nesse contexto, o papel do professor em sala de aula não é traduzir fielmente o texto do livro didático para os alunos, mas, sim, transformá-lo, "reescrevê-lo", criando, conforme admite Chevallard (2005) um metatexto. A transposição didática apresenta-se assim, como um elemento essencial na atuação do professor em sala de aula, pois é, a partir dessa transposição que os conteúdos serão construídos pelos alunos de forma que favoreça a sua aprendizagem, utilizando-se dos mais diversos recursos e materiais. O desafio do professor está na transformação dos conhecimentos científicos em conteúdos escolares, de modo que facilite a aprendizagem dos alunos.

É importante ressaltar que o saber escolar não pode ser diferente do saber científico, e que o saber científico ao ser construído pelo aluno com o auxílio do docente, sofre apenas mudanças adaptativas para se tornar saber escolar, sem perder a sua essência. Nesse sentido podemos perceber que os professores universitários ainda encontram muitas dificuldades no que diz respeito em transpor didaticamente um conteúdo e não utilizam as atividades experimentais como mediadora nesse processo.

\section{Atividades experimentais no Ensino Médio}

Carvalho (2010) discute que as práticas experimentais estão presentes no Ensino de Física da escola média desde o século XIX e, apesar disso, o uso dessas práticas 
ainda carece de olhares mais cuidadosos, principalmente durante a formação dos professores, pois, ainda hoje, a disciplina de Física, no Ensino Médio, apresenta enfoques essencialmente teóricos, centrando-se basicamente em conceitos abstratos (desvinculados da realidade), cálculos matemáticos e exercícios de fixação. Isso gera desinteresse e aversão a disciplina. Acreditamos que as disciplinas da Física Experimental da Licenciatura, devem ser repensadas para contribuir para a mudança dessa realidade, dando suporte para os alunos (futuros professores) estabelecerem vínculos entre a teoria e a prática, através de uma Transposição Didática efetiva dos saberes da Física.

A utilização das Práticas Experimentais no Ensino Médio é considerada como um meio para facilitar o aprendizado de conteúdos trabalhados em sala de aula, além de poder propiciar o desenvolvimento de habilidades essenciais para a formação dos educandos. Nesse sentido, as atividades experimentais podem se transformar em importantes aliadas do professor no desenvolvimento de trabalhos educativos voltados para o ensino dos conteúdos científicos (BORGES, 2002; ROSA, 2003; GASPAR e MONTEIRO, 2005; LABURÚ et al., 2007; CARVALHO, 2010, SILVA e ROSA, 2016).

Apesar de vários anos de pesquisa em Ensino de Física, a concepção empirista de ensino continua predominando nas aulas de Física no Ensino Médio. Atualmente, como verificamos na nossa pesquisa, os processos de ensino e aprendizagem continuam sendo tradicionais, centrados no professor, baseadas no livro didático, listas de exercícios e provas com caráter de testagem. Acreditamos que o ensino para a testagem é treinamento, é comportamentalismo, aquele em que o aluno deve dar a "resposta correta", ou seja, apresentar o comportamento esperado sem entrar na questão do sentido e do significado (MOREIRA, 2018).

As atuais aulas de Física no Ensino Médio, ainda estão baseadas no modelo da racionalidade, refletindo a sua formação ambiental universitária e da Educação Básica, baseada na lógica disciplinar e tratando os alunos como espíritos virgens, não levando em consideração suas crenças e representações anteriores a respeito do ensino, conforme descreve TARDIF (2018). As aulas são apoiadas nos livros textos que desprezam os processos de transposição dos saberes.

Os professores relatam que acreditam na importância das atividades experimentais e concordam que ela pode ajudar nos processos de ensino e aprendizagem e o mais estarrecedor é que a grande maioria não usa e os poucos que utilizam, o 
fazem esporadicamente. O principal argumento descrito é o tempo que essas atividades demandam, principalmente, para o seu desenvolvimento em sala de aula. Acreditamos que os professores não conseguem reconhecerem-se protagonistas do seu próprio tempo na escola, ou seja, não compreendem que os tempos da escola, são criações deles mesmos, em seus projetos pedagógicos.

Verificamos que os professores do Ensino Médio não conhecem uma fundamentação teórico-pedagógica adequada que oriente o planejamento e o desenvolvimento das práticas experimentais no ambiente escolar e, também por isso, acabem por abandoná-las. Desconhecem como essas práticas podem ser usadas para fazer a Transposição Didática dos saberes físicos dentro de uma concepção construtivista da produção da Ciência. Nesse contexto, as atividades experimentais teriam função mediadora no ensino dos conteúdos de Física e não do método experimental (ALVES FILHO, 2000).

Todos os professores que relatam utilizar as atividades experimentais, mesmo esporadicamente (menos de $20 \%$ do total), dizem que as fazem de maneira demonstrativa com o objetivo de os alunos observarem os fenômenos envolvidos e a partir daí desenvolvem, de maneira expositiva a explicação dos conceitos. Percebemos que eles desconhecem que uma aula de demonstração, deve ser investigativa e criar, além do fenômeno em si, oportunidade para a construção científica de um conceito ligado a esse fenômeno e é esse o grande cuidado que temos de tomar. "Deve-se estar consciente da epistemologia da Ciência e saber diferenciar entre um fenômeno e os conceitos envolvidos" (CARVALHO, 2010). Carvalho (2010) mostra que o fenômeno pode ser mostrado e o conceito é abstrato e não está diretamente visível.

Precisamos superar a falsa e ingênua expectativa de que basta o aluno observar uma atividade experimental para que determinado conteúdo seja aprendido (GASPAR, 2014). A construção do conceito deve ser feita pela interação entre o fenômeno e o discurso de professores e alunos e, a partir dessa sistematização, precisa ser traduzido em uma linguagem matemática, que será retomado a seguir.

Essa visão ingênua está baseada nas crenças empiristas de que se tem que observar para construir uma teoria. Este fato mostra uma questão importante a considerar no planejamento das atividades experimentais, que é a possibilidade de enriquecer o conhecimento sobre a natureza da Ciência, pois esse conhecimento influencia a aprendizagem dos estudantes na atividade experimental. Consideramos 
que as universidades têm que investir em trabalhar a Epistemologia e a História e Filosofia da Ciência nas disciplinas experimentais, além de disciplinas específicas.

Nesse contexto, acreditamos que essas deficiências estão relacionadas à formação inicial e os próprios entrevistados diziam que sentiam falta de uma aproximação entre os conteúdos específicos e os da formação pedagógica. Especificamente nas disciplinas de Física Experimental os formadores se preocupavam principalmente com comprovações, validações, verificações de leis ou princípios e determinação de erros, valorizando as concepções empírico-indutivistas da Ciência. Isso evidenciava claramente que as práticas experimentais tinham como objetivo o ensino do método experimental e não a sua utilização como mediadora dos processos de transposição dos saberes físicos.

Os professores formadores, principalmente das disciplinas de Física Experimental, deveriam entender que existem grandes diferenças entre a formação para o magistério e a formação para a pesquisa, apesar de ambas necessitarem de uma sólida construção teórica. Para o magistério, também é necessária uma formação pedagógica, que não pode ficar restrita as disciplinas da Educação e a formação para a práxis, como prevê a legislação e deve permear todo o curso.

Acreditamos que os professores das disciplinas de Física Experimental para a Licenciatura deveriam assumir uma postura construtivista, que já foi proposta por Alves Filho em 2002 e até hoje não foi adotada. O autor explica:

[...] a sua adoção como referência implicaria aceitá-la nas diferentes esferas do saber, desde o processo de construção do saber sábio (domínio específico da atual epistemologia), passando pelo processo transformador deste para o saber a ensinar (domínio da teoria dos currículos), até o espaço escolar onde ocorre a transposição do saber a ensinar para saber ensinado (domínio das teorias didáticas) e, por que não, para o saber aprendido (domínio das teorias cognitivas) (ALVES FILHO, 2002, p.1).

Outro fator preocupante que foi descrito por praticamente $80 \%$ dos pesquisados e que mais prejudica a aprendizagem em Física no Ensino Médio é a falta de pré-requisitos matemáticos dos alunos. Isto é um equívoco, como apresenta Pietrocola (2010), e não é tratado dentro da licenciatura em Física. Este tipo de raciocínio subjaz a ideia de que a Física se vale da Matemática, enquanto instrumento para enunciar suas leis e princípios, desconsiderando que existe uma relação muito mais complexa entre ambas as disciplinas, que faz da Matemática uma linguagem estruturante do conhecimento físico. Nesse sentido de muito pouco ou de quase nada 
interessa a vivência isolada do aluno no contexto próprio da Matemática, sem um esforço específico de introduzi-lo na "arte" da estruturação do pensamento através da Matemática.

A questão central é perceber que não se trata apenas de saber Matemática para poder operar as teorias Físicas que representam a realidade, mas de saber apreender teoricamente o real através de uma estruturação matemática. Dominar operações, regras e técnicas em Matemática é condição necessária, mas não suficiente, para se fazer uso organizacional da mesma em domínios externos a ela, ou seja, é preciso que sejam desenvolvidas outras habilidades estruturantes para que o estudante seja capaz de pensar matematicamente para resolver um problema de Física (KARAN e PIETROCOLA, 2009).

\section{Considerações finais}

Acreditamos que os cursos de Licenciatura em Física, de um modo geral, necessitam mudar o foco da formação, principalmente nas disciplinas de Física Experimental, que deveriam ter como grande objetivo a elevação das práticas experimentais a uma metodologia que demonstrasse eficiência no ensino de Física. Nessa perspectiva, a atividade experimental, deve ser entendida como um objeto didático a partir da Transposição Didática de concepção construtivista da experimentação. Também é necessário que seja discutida a importância dos problemas que originaram a construção dos conhecimentos científicos, em especial, quais foram as dificuldades e obstáculos epistemológicos; discutir como levar em conta as ideias prévias dos estudantes, fundamental na proposta construtivista; conhecer as orientações metodológicas empregadas na construção dos conhecimentos.

Essa mudança implica em considerar a necessidade de o professor conhecer não apenas os conteúdos da Física, mas também conhecer os conteúdos de Didática e de Pedagogia, de modo a poder planejar e implementar propostas para o ensino de conhecimentos científicos, além de avaliar se houve a aprendizagem desses e a relação das ações de ensino com a aprendizagem na expectativa de aprimorar sua prática (CARVALHO e SASSERON, 2018).

Para Yamazaki e Yamazaki (2017) esse cenário é complexo, na medida em que os próprios docentes de ensino universitário, que formam novos professores, não se adaptam às atuais demandas educacionais, no âmbito didático-pedagógico, resistindo 
a mudanças e inovações para sala de aula. $\mathrm{O}$ autor justifica que essa atitude revela uma compreensão epistemológica enraizada sobre ensino e aprendizagem que foi incorporada durante muitos anos escolares e universitários.

Refletindo sobre nosso objeto de estudo, as práticas experimentais, constamos que os professores do Ensino Médio concebem experimentos como estratégias didáticas importante para que o ensino seja mais eficiente. Contudo, os dados mostram que os professores raramente as utilizam e quando o fazem, utilizam dentro de uma compreensão empirista.

O processo de formação de professores de Física tem que prepará-los para a aquisição e o desenvolvimento de saberes de natureza diversa (científicos, pedagógicos-didáticos - incluindo a práxis -, organizacionais), desde o conhecimento do saber fazer até os processos de aprender a ensinar. As práticas experimentais, no ensino de Física, podem otimizar e contribuir para uma qualificação do ensino dessa área. É necessário que os formadores se conscientizem das potencialidades educativas advindas do trabalho experimental e assim adotem práticas didático-pedagógicas, como a sua utilização nos processos de Transposição Didática dos saberes físicos.

Por outro lado, se os programas das disciplinas, durante a formação inicial do professor de Física, não possibilitar articulações necessárias às perspectivas do professor do Ensino Médio, o profissional em atuação terá pela frente um problema a ser enfrentado para o qual não foi formado. Esse cenário, contudo, pode ser modificado se o processo de formação de professores de Física prepará-los para a aquisição e o desenvolvimento de saberes de natureza diversa (científicos, pedagógicos-didáticos - incluindo a práxis -, organizacionais), desde o conhecimento do saber fazer até os processos de aprender a ensinar. As práticas experimentais, no ensino de Física, podem otimizar e contribuir para uma qualificação do ensino dessa área. É necessário que os formadores se conscientizem das potencialidades educativas advindas do trabalho experimental e assim adotem práticas didático-pedagógicas, como a sua utilização nos processos de Transposição Didática dos saberes físicos. 


\section{Contributions of the experimental disciplines of the license in physics for the training of teaching knowledge}

\section{Abstract}

Studies points out gaps in the initial education of teachers, mainly due to the separation between disciplinary and pedagogical knowledge. They also show that laboratory classes are associated with closed scripts and centered on the application model, prioritizing specific knowledge of Physics and the scientific method, to the detriment of an appropriate pedagogical training for its use at the High School, ignoring its potential mediator for the Didactic Transposition of knowledge. This work presents the results of a research that was developed with the aim of evaluating the contributions of the Experimental Physics disciplines in Physics degrees for the construction of the teaching knowledge of future teachers, based on the concepts of knowledge proposed by Tardif and the Didactic Transposition in Chevallard's vision. The research methodology is qualitative, of the case study type, referenced in Stake's perspective. Considering the instrument for data collection, questionnaires were applied online to 65 professors from all over Brazil, and semi-structured interviews, applied to 16 professors graduated from the universities of Rio Grande do Sul. The research showed the need for an update of the Experimental Physics subjects in the Physics Degree, so that they contribute significantly to the training of teachers who work in high school.

Keywords: Physics teaching; teacher training; Experimental Physics.

\section{Referências}

ALVES FILHO, J. P. Atividades experimentais: do método à prática construtivista. Tese de Doutorado, UFSC, Florianópolis, 2000.

ALVES FILHO, J. P. Atividade experimental: uma alternativa na concepção construtivista. VIII Encontro de Pesquisa em Ensino de Física, 2002. Disponível em http://www.cienciamao.usp. br/dados/epef/_atividadeexperimentaluma.trabalho.pdf Acesso: 12/10/2019.

BORGES, A. T. Novos rumos para o laboratório escolar de Ciências. Caderno Brasileiro de Ensino de Física, v. 19, n.3, p.291-313, 2002.

CACHAPUZ, A., GIL-PÉREZ, D., CARVALHO, A. M. P., PRAIA, J. e VILCHES, A. A necessária renovação no Ensino de Ciências. 2. Ed. São Paulo: Cortez, 2011.

CARVAlho, A. M. P. As Práticas experimentais no Ensino de Física. In: Carvalho, A. M. P. Ensino de Física. São Paulo: Cengage Learning, 2010.

CASTRO, A. D. Prefácio. In: Carvalho, A. M. P. Ensino de Ciências: Unindo a Pesquisa e a Prática. São Paulo: Pioneira Thonson Learning, 2004.

CHEVALlARD, Y. La Transposición didáctica. Buenos Aires: Aique, 2005.

GARCIA, K. G. e POZO, J. I. Concepções de professores de Física sobre ensino-aprendizagem e seu processo de formação: um estudo de caso. Investigações em Ensino de Ciências. v.22(2), p. 96-119, 2017. 
GASPAR, A. e MONTEIRO, I. Atividades experimentais de demonstrações em sala de aula: uma análise segundo o referencial da teoria de Vygotsky. Investigações em Ensino de Ciências V10(2), pp. 227-254, 2005.

GASPAR, A. Experiências de Ciências. São Paulo: Editora Livraria da Física, 2014.

IMBERNÓN, F. A formação docente e profissional; formar-se para a mudança e a incerteza. São Paulo, Cortez, 2011.

KARAN, R. A. S.; PIETROCOLA, M. Habilidades técnicas versus habilidades estruturantes: resolução de problemas e o papel da matemática como estruturante do pensamento físico. ALEXANDRIA Revista de Educação em Ciência e Tecnologia, v.2, n.2, p.181-205, jul. 2009.

MOREIRA, M. A. Uma análise crítica do ensino de Física. Estudos Avançados, vol.32 n.94 São Paulo Sept./Dec., 2018.

PIETROCOLA, M. A Matemática como linguagem estruturante do pensamento físico. In: Carvalho, A. M. P. Ensino de Física. São Paulo: Cengage Learning, 2010.

ROSA, C. W. Concepções teóricos metodológicas no laboratório didático de Física na Universidade de Passo Fundo. Revista Ensaio, v.5, n 2, p.13-27, 2003.

SABINO, A. R.; PIETROCOLA, M. Saberes docentes desenvolvidos por professores do Ensino Médio: um estudo de caso com a inserção da Física Moderna. Investigações em Ensino de Ciências - V21(2), pp. 200-216, 2016.

SILVA, B. L.; ROSA, C. W. Atividades experimentais de física: tendências nas pesquisas nacionais na área de ensino. V Seminário Nacional de Ensino de Ciências e Tecnologia (V SINECT), 2016.

STAKE, R. E. A arte de investigação com estudos de caso. Lisboa: Calouste Gulbenkian, 2009.

STAKE, R. E. Investigación com estúdio de casos. Madri: Ediciones Morata, 2007.

TARDIF, M. Saberes profissionais dos professores e conhecimentos universitários: elementos para uma epistemologia da prática profissional dos professores e suas consequências em relação à formação para o magistério. Rev. Bras. de Educação, Rio de Janeiro, n. 13, p. 1-20, jan./fev./ mar./abr. 2000.

TARDIF, M. Saberes Docentes e Formação profissional. Petrópolis: Editora Vozes, 17. Ed., 2018.

TARDIF, M.; RAYMOND, D. Saberes, tempo e aprendizagem do trabalho no magistério. Educ. Soc., vol.21, no.73, p.209-244, 2000.

YAMAZAKI, S. C. e YAMAZAKI, R. M. O. Experimentos no Ensino de Física: um olhar de viés epistemológico. Revista Exitus, v. 7, n. 3: p. 38-63, abr. 2017.

YAMAZAKI, S. C.; ANGOTTI, J. A P; DELIZOICOV, D. Aprender como ensinar física através do livro texto de ciclo básico universitário: um fenômeno didático em questão. Amazônia: Revista de Educação em Ciências e Matemática, v.13 (28), p.05-22. Jun-Dez 2017. 